\title{
Erratum to: Neurogenic differentiation from adipose-derived stem cells and application for autologous transplantation in spinal cord injury
}

Yong Zhao $\cdot$ Hui Jiang $\cdot$ Xin-wei Liu

Jian-Ting Chen $\cdot$ Liang-Bi Xiang $\cdot$ Da-Peng Zhou

Published online: 31 January 2015

(C) Springer Science+Business Media Dordrecht 2015

\section{Erratum to: Cell Tissue Bank \\ DOI 10.1007/s10561-014-9476-3}

Unfortunately, in the original publication of the article, the authors affiliation is incorrectly published. It is corrected in this erratum.

The online version of the original article can be found under doi:10.1007/s10561-014-9476-3.

Y. Zhao $\cdot$ H. Jiang $\cdot$ J.-T. Chen $(\bowtie)$

Department of Orthopedics, Nanfang Hospital of Southern

Medical University, Guangzhou 510515,

Guangdong Province, China

e-mail: jiantingchenprof@163.com

Y. Zhao · X. Liu · L.-B. Xiang · D.-P. Zhou Department of Orthopedics, General Hospital of Shenyang Military Area Command of Chinese PLA, Rescue Center of Severe Wound and Trauma of Chinese PLA, Shenyang 110016, Liaoning Province, China 